\title{
A novel organic-inorganic hybrid based on Anderson-type polyoxometalate: $\mathrm{H}\left(\mathrm{C}_{5} \mathrm{~N}_{5} \mathrm{H}_{5}\right)_{2}\left(\mathrm{C}_{5} \mathrm{~N}_{5} \mathrm{H}_{6}\right)_{2}\left[\mathrm{Al}\left(\mathrm{OH}_{6}\right) \mathrm{Mo}_{6} \mathrm{O}_{18}\right] \cdot 10 \mathrm{H}_{2} \mathrm{O}$
}

\author{
SAFA THABET*, BRAHIM AYED and AMOR HADDAD \\ Laboratoire de matériaux et cristallochimie, faculté des sciences Monastir, Avenued'environnement, \\ 5019 Monastir, Tunisie
}

MS received 25 March 2013; revised 27 September 2013

\begin{abstract}
A new organic-inorganic hybrid compound, $\mathrm{H}\left(\mathrm{C}_{5} \mathrm{~N}_{5} \mathrm{H}_{5}\right)_{2}\left(\mathrm{C}_{5} \mathrm{~N}_{5} \mathrm{H}_{6}\right)_{2}\left[\mathrm{Al}\left(\mathrm{OH}_{6}\right) \mathrm{Mo}_{6} \mathrm{O}_{18}\right] \cdot 10 \mathrm{H}_{2} \mathrm{O}$, has been synthesized and structurally characterized by single crystal $\mathrm{X}$-ray diffraction, elemental analyses, IR, UV-Vis spectra and thermogravimetric analyses. This compound crystallized in the triclinic system, space group $P$-1, with $a=8.033(5) \AA, b=9.960(4) \AA, c=16.797(7) \AA, \alpha=73.43(3)^{\circ}, \beta=87.85(1)^{\circ}, \gamma=81.47(1)^{\circ}$ and $Z=1$. The crystal structure can be described by infinite polyanions $\left[\mathrm{Al}(\mathrm{OH})_{6} \mathrm{Mo}_{6} \mathrm{O}_{18}\right]^{3-}$ organized in layers parallel to the $c$-direction alternating with organic cations associated in ribbons spreading along the $b$-direction. Multiple hydrogen bonds originating from amine, hydroxyl groups and water molecules connect different components of the lattice.
\end{abstract}

Keywords. Polyoxometalate; organic-inorganic hybrid; Anderson anion; adenine; crystal structure.

\section{Introduction}

Polyoxometalates (POMs) have been employed as inorganic building blocks for the construction of nanostructured clusters or one-, two- and three-dimensional extended open frameworks owing to their discrete structures and notable photochemical properties, which lead to a vast range of potential applications in different areas such as catalysis, electrochemistry, medicine and magnetism (Pope 1983; Kozhenikov IV 1998; Clemente-Juan and Coronado 1999a; Keita et al 2006; Proust et al 2008). Especially, spherical surface of POM anions gives a better opportunity to form hydrogen bond interactions with the organic/inorganic moieties. So far, several successful strategies have been developed to design POMbased supramolecular compounds (Ren et al 2006; Wang et al 2010; Yan et al 2011). Supramolecular structures of POMs with organic molecules such as TTF type (Peng et al 1999; Ouahab et al 2003), organic amines (Zhang et al 2009) and others (An et al 2008; Liu et al 2009; Ma et al 2011) have been successfully constructed. These materials are particularly interested in some important aspects of chemistry such as catalysis, nonlinear optical properties and charge transfer salts based on their supramolecular assembly (Gomez-Garcia et al 1994; Hagraman et al 1999; Finn et al 2000).

In this paper, we chose heteropolymolybdate cluster as the building block and flexible adenine molecule as the

\footnotetext{
*Author for correspondence (safathabet@hotmail.fr)
}

structure-directing agent to construct supramolecular compounds: $\mathrm{H}\left(\mathrm{C}_{5} \mathrm{~N}_{5} \mathrm{H}_{6}\right)_{2}\left(\mathrm{C}_{5} \mathrm{~N}_{5} \mathrm{H}_{6}\right)_{2}\left[\mathrm{Al}\left(\mathrm{OH}_{6}\right) \cdot \mathrm{Mo}_{6} \mathrm{O}_{18}\right] \cdot 10 \mathrm{H}_{2} \mathrm{O}$.

\section{Experimental}

\subsection{Materials and general methods}

All reagents were purchased commercially and used without further purification. The infrared spectra were recorded as $\mathrm{KBr}$ pellets, in the $4000-400 \mathrm{~cm}^{-1}$ range on a Nicolet 470 FTIR spectrophotometer (resolution: $0 \cdot 125 \mathrm{~cm}^{-1}$ ). UV-Visible absorption spectrum was recorded on a Perkin-Elmer Lambda 19 spectrophotometer. A Setaram TG-DTA92 thermo analyser was used to perform thermal treatment on samples of the title compound. TG-DTA thermograms were obtained with $30.20 \mathrm{mg}$. Samples were placed in an open platinum crucible and heated in air with $10^{\circ} \mathrm{C} / \mathrm{min}$ heating rate; an empty crucible was used as reference.

\subsection{Chemical preparation}

To a solution of $\left(\mathrm{NH}_{4}\right)_{6} \mathrm{Mo}_{7} \mathrm{O}_{24} \cdot 4 \mathrm{H}_{2} \mathrm{O} \quad(0.307 \mathrm{~g})$ and $\mathrm{Al}\left(\mathrm{NO}_{3}\right)_{9} \cdot 9 \mathrm{H}_{2} \mathrm{O}(0 \cdot 15 \mathrm{~g})$ in $20 \mathrm{~mL}$ of distilled water was added, dropwise, $8 \mathrm{~mL}$ of glacial acetic acid containing $0.04 \mathrm{~g}$ of adenine that was stirred for $1 \mathrm{~h}$ at room temperature. The filtrate was kept for 4 days at room temperature and then colourless block crystals suitable for (1) were collected in about $40 \%$ yield (based on Mo). Elem. Anal. Found: Mo, 33.65; Al, 1.53; C, 14.87; H, 
2.96 and N, 16.23; (\%). Calcd: Mo, 33.68; Al, 1.58; C, $14 \cdot 05 ; \mathrm{H}, 2.48$ and $\mathrm{N}, 16 \cdot 39(\%)$.

\section{$2.3 \quad X$-ray crystallography}

Compound (1) was stable under ambient conditions and colourless single crystal was carefully selected and glued on the end of a glass capillary. X-ray diffraction data were collected in the range of $2 \cdot 2<\theta<27$ on a EnrafNonius CAD-4 diffractometer, operating at $293 \mathrm{~K}$ with $\operatorname{MoK} \alpha(\lambda=0.71073 \AA)$ (CAD4, Solfware, version 5.0, Enraf Nonius, Delft, The Netherlands, 1989). A total of 7594 reflections were measured $(-10<h<3,-12<k<12$, $-21<l<21)$. The structure of 1 was solved by the Patterson method and refined by full-matrix least-squares on $F^{2}$ using the SHELXL 97 software (Sheldrick 1997, SHELXS-97). All non-hydrogen atoms were refined anisotropically. Other hydrogen atoms were not located. The details of data collection and structure refinements for this compound are listed in table 1 .

\section{Results and discussion}

\subsection{Structure description}

Single-crystal X-ray analysis reveals that this material consists of one Anderson-B polyoxoanions $\left[\mathrm{Al}(\mathrm{OH})_{6}\right.$ $\left.\mathrm{Mo}_{6} \mathrm{O}_{18}\right]^{3-}$, four adenine molecules and ten free water molecules.

A projection of the structure showing displacement ellipsoids, is presented in figure 1. From a general point of view (figure 2), this structure can be described as a succession of an alternating organic and inorganic sheets extending along the $c$-direction. A purely organic sheet presents a stack in zigzag of adenine. The second is characterized by alternating water molecules and $\left[\mathrm{Al}(\mathrm{OH})_{6} \mathrm{Mo}_{6} \mathrm{O}_{18}\right]^{3-}$ anionic clusters. To the best of our knowledge, no analogous 3D structure consisting of Anderson-type POM building blocks and adenine bases has been reported in literature.

The polyoxoanion $\left[\mathrm{Al}(\mathrm{OH})_{6} \mathrm{Mo}_{6} \mathrm{O}_{18}\right]^{3-}$ is formed by close packing of oxygen atoms with $\mathrm{Al}$ and Mo atoms in

Table 1. Crystal structure data for 1 .

\begin{tabular}{ll}
\hline Chemical formula & $\mathrm{C}_{20} \mathrm{H}_{46} \mathrm{~N}_{20} \mathrm{O}_{34} \mathrm{AlMo}_{6}$ \\
Formula weight & $1709 \cdot 3 \mathrm{~g} \mathrm{~mol}^{-1}$ \\
Crystal system & Triclinic \\
Space group/Z & $\mathrm{P}-1 / 1$ \\
$a(\AA)$ & $8 \cdot 033(5)$ \\
$b(\AA)$ & $9 \cdot 960(4)$ \\
$c(\AA)$ & $16 \cdot 797(7)$ \\
$\alpha(\AA)$ & $73 \cdot 43(3)^{\circ}$ \\
$\beta\left({ }^{\circ}\right)$ & $87 \cdot 85(1)$ \\
$\gamma\left({ }^{\circ}\right)$ & $81 \cdot 47$ \\
Volume $\left(\AA^{3}\right)$ & $1274 \cdot 03$ \\
Calculated density $\left(\mathrm{g} \mathrm{cm}^{-1}\right)$ & $2 \cdot 23$ \\
Absorption coefficient $\left(\mathrm{mm}^{-1}\right)$ & 1.56 \\
No. of independent reflections & $5508\left[R_{\text {int }}=0.022\right]$ \\
Unic reflections included & 4705 \\
No. of refined parameters & 378 \\
Goodness-of-fit on $F^{2}$ & 1.02 \\
$R$ (anisotropic) & 0.067 \\
$R_{w}$ (anisotropic) & $0 \cdot 199$ \\
\hline
\end{tabular}

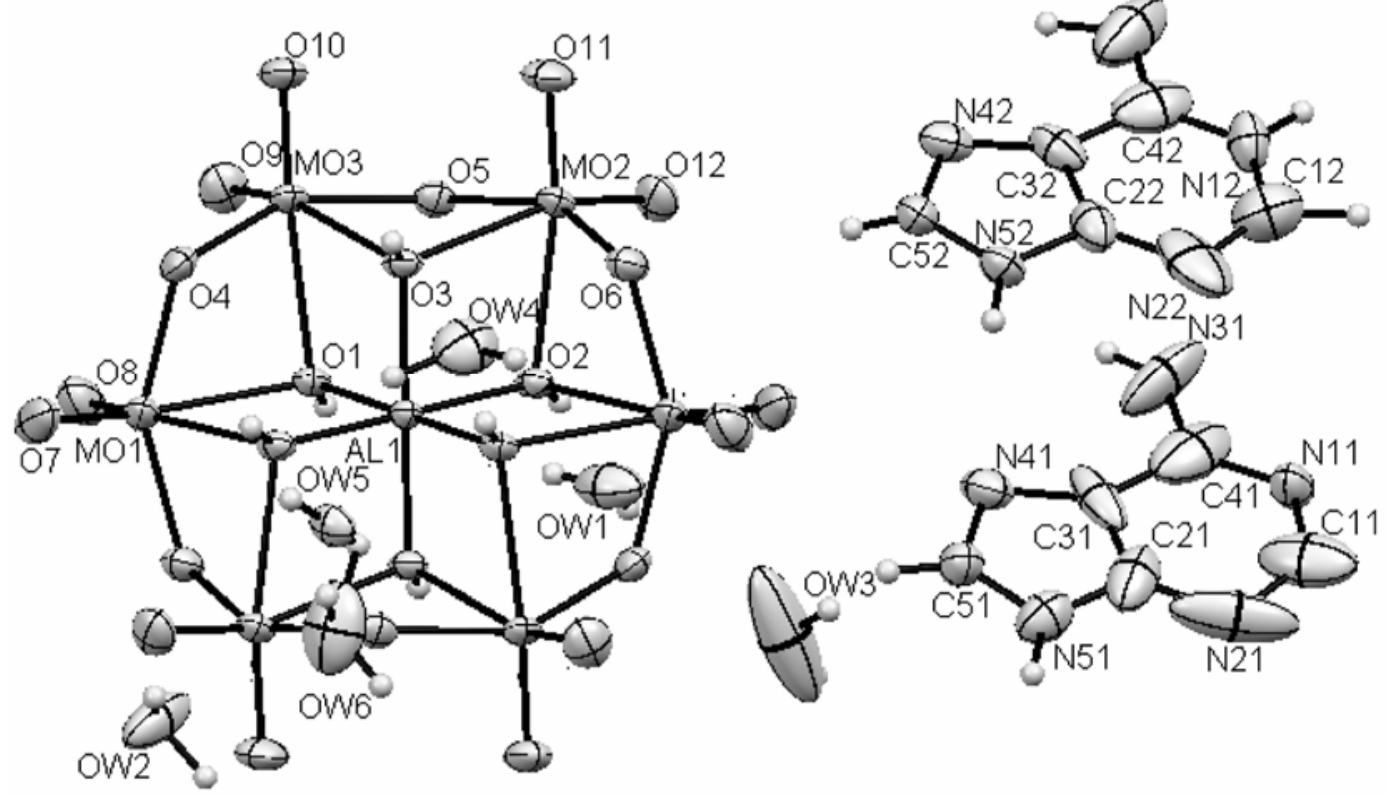

Figure 1. An ORTEP drawing of compound 1. 


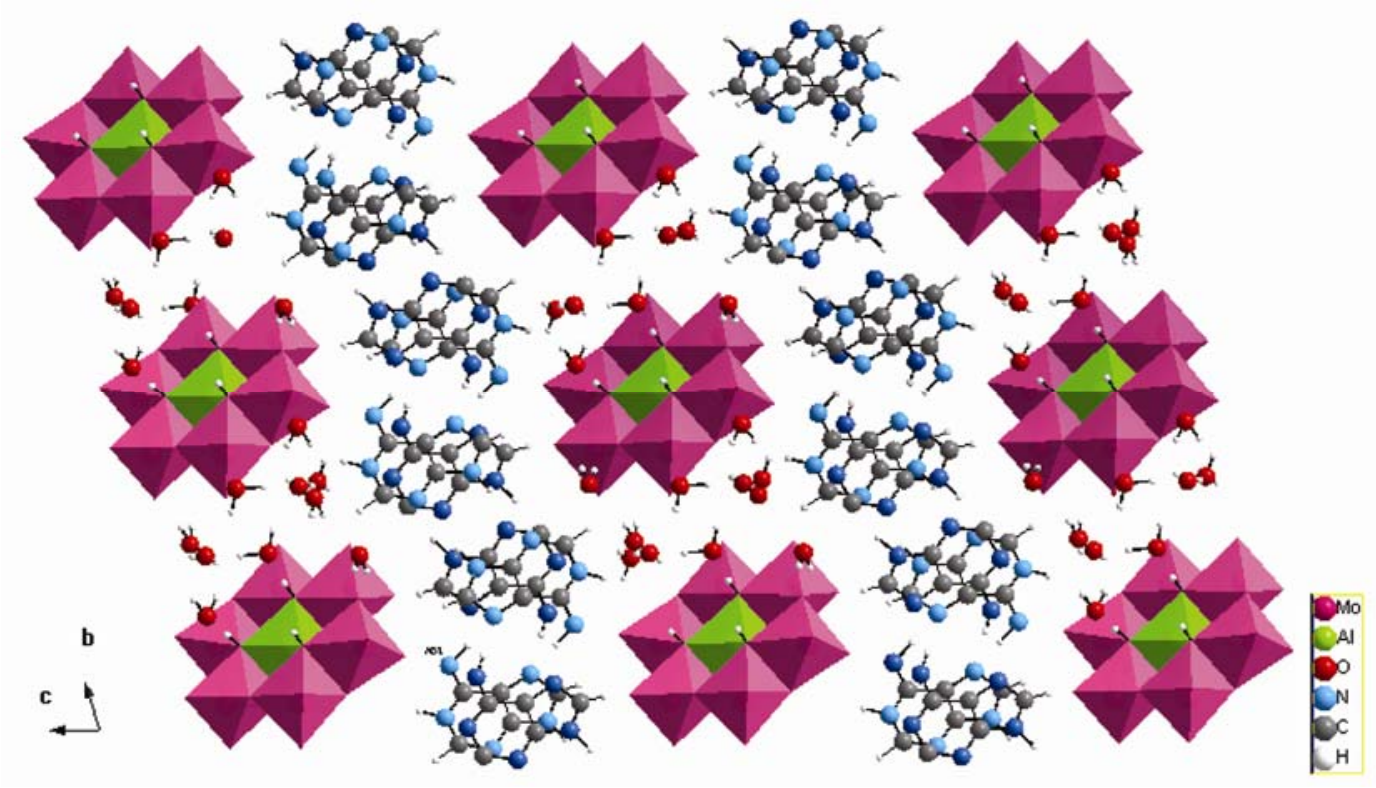

Figure 2. View of three-dimensional network of the compound along the $a$-axis.

the distorted octahedral voids. A perspective view of the $\left[\mathrm{Al}(\mathrm{OH})_{6} \mathrm{Mo}_{6} \mathrm{O}_{18}\right]^{3-}$ anion with its numbering scheme is shown in figure 1. In this anion, the octahedral unit, $\mathrm{AlO}_{6}$, is surrounded by six $\mathrm{MoO}_{6}$ groups. The six Mo atoms, forming a hexagon around $\mathrm{Al}$, give overall approximate $D_{3 \mathrm{~d}}$ symmetry to the anion. Three kinds of oxygen atoms exits in this polyoxoanion according to the manner of oxygen coordination: the terminal oxygen $O_{\mathrm{t}}$, with the molybdenum-oxygen distances of $\mathrm{Mo}-\mathrm{O}_{\mathrm{t}}$, $1.698(5)-1.737(5) \AA$; central oxygen $\left(O_{c}\right)$ linked to two molybdenum atoms and the aluminum atom, with the molybdenum-oxygen distances of $\mathrm{Mo}-\mathrm{O}_{\mathrm{c}}, 2 \cdot 280(4)$ $2 \cdot 317(4) \AA$; the bridging oxygen $\left(\mathrm{O}_{\mathrm{b}}\right)$ common to two molybdenum octahedra, with the molybdenum-oxygen distances of $\mathrm{Mo}-\mathrm{O}_{\mathrm{b}}, 1.909(4)-1.958(5) \AA$. These values are similar to those found in other compounds (An et al 2004, 2005; Xiao et al 2005). The Mo-Mo distances lie in the $3 \cdot 310(2)-3 \cdot 338(2) \AA$ range. The Al-Mo distances are in the $3 \cdot 312(2)-3 \cdot 327(7) \AA$ ranges. In the crystal structure, central Al-O distances vary from 1.904(5) to $1.910(5) \AA$. The bond angles of $\mathrm{O}-\mathrm{Al}-\mathrm{O}_{\text {cis }}$ range from $83.8(2)^{\circ}$ to $96 \cdot 2(2)^{\circ}$ and $\mathrm{O}-\mathrm{Al}-\mathrm{O}_{\text {trans }}$ is $180^{\circ}$. The bridging oxygen atoms around the $\mathrm{Al}^{3+}$ ion are protonated, which makes the anion become both the acceptor and the donor of hydrogen bond. The bond lengths within the anion are listed in tables 2 and 3.

BVS calculations (Softbv web page by Prof. Stefan Adams, http://kristall.uni.mki.gwdg.de/softbv) revealed that all the molybdenum atoms have valence sums ranging from 5.970 to 6.045 , with an average value of 6.001 , close to the ideal value of 6 for $\mathrm{Mo}^{\mathrm{VI}}$. The calculated average value of aluminum (+III), oxygen (-II) atoms are, respectively $3 \cdot 071$ and 1.970 .
Four amine molecules, corresponding to two crystallographically independent moieties are inserted between layers of water molecules. As listed in table 4, the adenine base associated into dimers by $\mathrm{N}-\mathrm{H} \cdots \mathrm{N}$ hydrogen bonds (figure 3 ). These dimers are further hydrogen bonded to $\mathrm{Ow}(3)$ and $\mathrm{Ow}(5)$ in order to form an unprecedented $1 \mathrm{D}$ chain. The typical hydrogen bonds are Ow(3)... $\mathrm{N}(11), 2.504 \AA$ and $\mathrm{N}(12) \ldots \mathrm{Ow}(5), 1.987 \AA$. In fact, 1D Anderson-type POM building blocks were previously reported such as the $\left[\left(\mathrm{Na}\left(\mathrm{H}_{2} \mathrm{O}\right)_{2}\left(\mathrm{Al}(\mathrm{OH})_{6} \mathrm{Mo}_{6} \mathrm{O}_{18}\right)\right]_{n}^{n-}\right.$ (Thabet et al 2012), $\left[\left(\mathrm{H}_{2} \mathrm{O}\right)_{14} \mathrm{Cd}_{3}\left(\mathrm{Cr}(\mathrm{OH})_{6} \mathrm{Mo}_{6} \mathrm{O}_{18}\right)_{2}\right]$ ( An et al 2009), $\left[\left(\mathrm{H}_{2} \mathrm{O}\right)_{6} \mathrm{Dy}\left(\mathrm{Cr}(\mathrm{OH})_{6} \mathrm{Mo}_{6} \mathrm{O}_{18}\right)\right]$ (Xiao et al $2005)$ chains in which the polyanions are linked by $\mathrm{Na}^{+}$, $\mathrm{Cd}^{2+}$ and $\mathrm{Dy}^{3+}$ ions, respectively. However, to the best of our knowledge, this is a rare example where polyanions coordinate with organic ligand without introduction of the metal cations to generate such polymeric 1D structure.

In the $1 \mathrm{D}$ chain, there exists striking $\pi-\pi$ interactions between two adjacent adenine molecules with the average distance of aromatic units, $3.661 \AA$, which makes the chains more stable (figure S1). Finally, these chains are linked up together to form a 3D supramolecular network via strong hydrogen-bonding interactions among free water molecules and central and terminal oxygen atoms of polyoxoanion.

By comparison with the tautomeric forms of adenine (Taylor 1973; Hingerty et al 1981; Mohamed et al 2009), it can be assumed that both organic molecules adopt the $\mathrm{N}(5) \mathrm{H}$-amino configuration: the angles at $\mathrm{N}(4)$ of the present compound and all others in references agree well with the average value, $102 \cdot 6^{\circ}$, for an unprontonated $\mathrm{N}(4)$, but the angles at $\mathrm{N}(5)$ are all between 106.4 and $108 \cdot 1^{\circ}$ for a protonated $\mathrm{N}(5)$. The protonation of 
Table 2. The final atomic coordinates and equivalent temperature factors for 1 .

\begin{tabular}{lcccc}
\hline Atom & $X$ & $Y$ & $Z$ & Ueq \\
\hline Mo1 & $0 \cdot 107(5)$ & $0 \cdot 268(4)$ & $0 \cdot 182(1)$ & $0 \cdot 027(4)$ \\
Mo2 & $0 \cdot 235(6)$ & $0 \cdot 495(7)$ & $-0 \cdot 166(6)$ & $0 \cdot 02(4)$ \\
Mo3 & $0 \cdot 349(2)$ & $0 \cdot 269(3)$ & $0 \cdot 017(9)$ & $0 \cdot 0234)$ \\
Al & 0 & $0 \cdot 5$ & 0 & $0 \cdot 019(2)$ \\
O1 & $0 \cdot 064(4)$ & $0 \cdot 301(7)$ & $0 \cdot 042(7)$ & $0 \cdot 022(3)$ \\
O2 & $0 \cdot 027(2)$ & $0 \cdot 503(3)$ & $0 \cdot 111(0)$ & $0 \cdot 022(0)$ \\
O3 & $-0 \cdot 2313$ & $0 \cdot 496(3)$ & $0 \cdot 029(2)$ & $0 \cdot 021(8)$ \\
O4 & $0 \cdot 318(7)$ & $0 \cdot 301(0)$ & $0 \cdot 125(0)$ & $0 \cdot 028(6)$ \\
O5 & $0 \cdot 271(4)$ & $0 \cdot 303(5)$ & $-0 \cdot 095(0)$ & $0 \cdot 025(6)$ \\
O6 & $0 \cdot 137(0)$ & $0 \cdot 690(0)$ & $-0 \cdot 186(0)$ & $0 \cdot 029(8)$ \\
O7 & $0 \cdot 161(7)$ & $0 \cdot 299(0)$ & $0 \cdot 271(5)$ & $0 \cdot 050(8)$ \\
O8 & $0 \cdot 124(5)$ & $0 \cdot 087(8)$ & $0 \cdot 204(3)$ & $0 \cdot 045(2)$ \\
O9 & $0 \cdot 368(1)$ & $0 \cdot 090(0)$ & $0 \cdot 044(7)$ & $0 \cdot 040(3)$ \\
O10 & $0 \cdot 550(1)$ & $0 \cdot 311(5)$ & $0 \cdot 001(6)$ & $0 \cdot 035(5)$ \\
O11 & $0 \cdot 437(1)$ & $0 \cdot 528(5)$ & $-0 \cdot 183(3)$ & $0 \cdot 041(3)$ \\
O12 & $0 \cdot 175(4)$ & $0 \cdot 457(0)$ & $-0 \cdot 253(9)$ & $0 \cdot 038(4)$ \\
N11 & $0 \cdot 551(9)$ & $0 \cdot 169(6)$ & $0 \cdot 655(2)$ & $0 \cdot 040(6)$ \\
N21 & $0 \cdot 692(3)$ & $0 \cdot 040(3)$ & $0 \cdot 564(1)$ & $0 \cdot 122(0)$ \\
N31 & $0 \cdot 354(0)$ & $0 \cdot 373(3)$ & $0 \cdot 601(9)$ & $0 \cdot 097(5)$ \\
N41 & $0 \cdot 415(7)$ & $0 \cdot 342(5)$ & $0 \cdot 432(1)$ & $0 \cdot 041(3)$ \\
N51 & $0 \cdot 605(9)$ & $0 \cdot 156(6)$ & $0 \cdot 427(2)$ & $0 \cdot 049(1)$ \\
N12 & $0 \cdot 014(3)$ & $0 \cdot 209(8)$ & $0 \cdot 698(0)$ & $0 \cdot 044(3)$ \\
N22 & $0 \cdot 140(7)$ & $0 \cdot 085(2)$ & $0 \cdot 614(5)$ & $0 \cdot 085(6)$ \\
N32 & $-0 \cdot 184(1)$ & $0 \cdot 422(0)$ & $0 \cdot 656(3)$ & $0 \cdot 086(8)$ \\
N42 & $-0 \cdot 126(2)$ & $0 \cdot 382(3)$ & $0 \cdot 478(3)$ & $0 \cdot 039(3)$ \\
N52 & $0 \cdot 056(8)$ & $0 \cdot 192(5)$ & $0 \cdot 471(9)$ & $0 \cdot 034(6)$ \\
C11 & $0 \cdot 6506(2)$ & $0 \cdot 060(7)$ & $0 \cdot 636(1)$ & $0 \cdot 089(5)$ \\
C21 & $0 \cdot 597(1)$ & $0 \cdot 150(3)$ & $0 \cdot 507(7)$ & $0 \cdot 065(4)$ \\
C31 & $0 \cdot 478(9)$ & $0 \cdot 267(7)$ & $0 \cdot 510(0)$ & $0 \cdot 064(1)$ \\
C41 & $0 \cdot 462(1)$ & $0 \cdot 266(3)$ & $0 \cdot 593(4)$ & $0 \cdot 094(2)$ \\
C51 & $0 \cdot 500(4)$ & $0 \cdot 267(9)$ & $0 \cdot 385(3)$ & $0 \cdot 039(7)$ \\
C12 & $0 \cdot 115(0)$ & $0 \cdot 097(6)$ & $0 \cdot 689(4)$ & $0 \cdot 069(5)$ \\
C22 & $0 \cdot 048(4)$ & $0 \cdot 191(2)$ & $0 \cdot 553(5)$ & $0 \cdot 042(7)$ \\
C32 & $-0 \cdot 066(5)$ & $0 \cdot 309(8)$ & $0 \cdot 557(7)$ & $0 \cdot 043(5)$ \\
C42 & $-0 \cdot 080(4)$ & $0 \cdot 316(1)$ & $0 \cdot 641(6)$ & $0 \cdot 070(1)$ \\
C52 & $-0 \cdot 046(2)$ & $0 \cdot 308(3)$ & $0 \cdot 429(6)$ & $0 \cdot 036(4)$ \\
OW1 & $0 \cdot 250(4)$ & $0 \cdot 622(5)$ & $0 \cdot 165(7)$ & $0 \cdot 058(6)$ \\
OW2 & $0 \cdot 390(4)$ & $0 \cdot 861(0)$ & $-0 \cdot 217(9)$ & $0 \cdot 068(6)$ \\
OW3 & $0 \cdot 420(6)$ & $-0 \cdot 155(8)$ & $0 \cdot 173(6)$ & $0 \cdot 160(0)$ \\
OW4 & $-0 \cdot 141(3)$ & $0 \cdot 130(0)$ & $0 \cdot 014(2)$ & $0 \cdot 059(3)$ \\
OW5 & $0 \cdot 057(0)$ & $0 \cdot 137(9)$ & $-0 \cdot 129(3)$ & $0 \cdot 037(0)$ \\
OW6 & $0 \cdot 204(7)$ & $0 \cdot 090(5)$ & $-0 \cdot 154(9)$ & $0 \cdot 055(7)$ \\
\hline & & & &
\end{tabular}

the adenine base on the $\mathrm{N}(1)$ sites are reflected in the change in bond angle. The angle $\mathrm{C}(21)-\mathrm{N}(11)-\mathrm{C}(41)$ at the unprotonated $\mathrm{N}(11)$ atom is $118.42(2)^{\circ}$, while in the case of the protonated $\mathrm{N}(12)$ atom, the angle, $\mathrm{C}(22)$ $\mathrm{N}(12)-\mathrm{C}(42)$, is $125 \cdot 14(2)^{\circ}$. To our knowledge, this configuration is not very frequent in the solid state. These assumptions are also supported by the hydrogen bonding scheme: besides the interactions between $\mathrm{A}$ and $\mathrm{B}$, $\mathrm{N} 31 \ldots \mathrm{N} 42, \mathrm{~N} 32 \ldots \mathrm{N} 41$ and N51...N22, N52 ..N21, these organic bases exchange hydrogen bonds with two water molecules at $\mathrm{N}(1)$.

The abundant water molecules which are significant elements in our structure, act as good candidates of bonds. They form several hydrogen bonds with the nearest
Table 3. Selected bond lengths $(\AA)$ of 1 .

\begin{tabular}{|c|c|c|c|}
\hline Mo1-O7 & $1 \cdot 699(4)$ & $\mathrm{Al}-\mathrm{O} 3^{\mathrm{i}}$ & $1.907(3)$ \\
\hline Mo1-O8 & $1.729(6)$ & N11-C41 & $1 \cdot 341(8)$ \\
\hline Mo1-O4 & $1.94(1(1)$ & $\mathrm{N} 11-\mathrm{C} 11$ & $1 \cdot 363(3)$ \\
\hline Mo1-O6i & $1.949(9)$ & $\mathrm{N} 21-\mathrm{C} 11$ & $1 \cdot 319(6)$ \\
\hline Mo1-O1 & $2 \cdot 301(7)$ & $\mathrm{N} 21-\mathrm{C} 21$ & $1.385(3)$ \\
\hline Mo1-O2 & $2 \cdot 308(7)$ & N31-C41 & $1 \cdot 311(8)$ \\
\hline Mo2-O12 & $1.721(5)$ & N41-C51 & $1.329(8)$ \\
\hline Mo2-O11 & $1.696(3)$ & N41-C31 & $1 \cdot 381(6)$ \\
\hline Mo2-O5 & $1.934(2)$ & N51-C51 & $1 \cdot 309(7)$ \\
\hline Mo2-O6 & $1.919(1)$ & N51-C21 & $1 \cdot 381(6)$ \\
\hline Mo2-O3i & $2 \cdot 330(7)$ & $\mathrm{N} 12-\mathrm{C} 42$ & $1 \cdot 318(4)$ \\
\hline Mo2-O2i & $2 \cdot 276(7)$ & $\mathrm{N} 12-\mathrm{C} 12$ & $1 \cdot 279(5)$ \\
\hline Mo3-O9 & $1 \cdot 697(2)$ & $\mathrm{N} 22-\mathrm{C} 12$ & $1 \cdot 296(1)$ \\
\hline Mo3-O10 & $1.722(3)$ & N22-C22 & $1 \cdot 389(8)$ \\
\hline Mo3-O4 & $1 \cdot 913(5)$ & N32-C42 & $1 \cdot 327(3)$ \\
\hline Mo3-O5 & $1.940(9)$ & N42-C52 & $1 \cdot 333(8)$ \\
\hline Mo3-O1 & $2 \cdot 311(2)$ & N42-C32 & $1 \cdot 387(3)$ \\
\hline Mo3-O3i & $2 \cdot 305(2)$ & N52-C52 & $1 \cdot 352(5)$ \\
\hline $\mathrm{Al}-\mathrm{O} 1$ & $1.897(3)$ & N52-C22 & $1 \cdot 363(9)$ \\
\hline $\mathrm{Al}-\mathrm{O} 1^{\mathrm{i}}$ & $1.897(2)$ & C21-C31 & $1.402(6)$ \\
\hline $\mathrm{A} 1-\mathrm{O} 2$ & $1 \cdot 896(9)$ & C31-C41 & $1 \cdot 399(5)$ \\
\hline $\mathrm{A} 1-\mathrm{O} 2^{\mathrm{i}}$ & $1.896(9)$ & C22-C32 & $1.405(7)$ \\
\hline $\mathrm{Al}-\mathrm{O} 3$ & $1.907(3)$ & C $32-\mathrm{C} 42$ & $1.419(9)$ \\
\hline
\end{tabular}

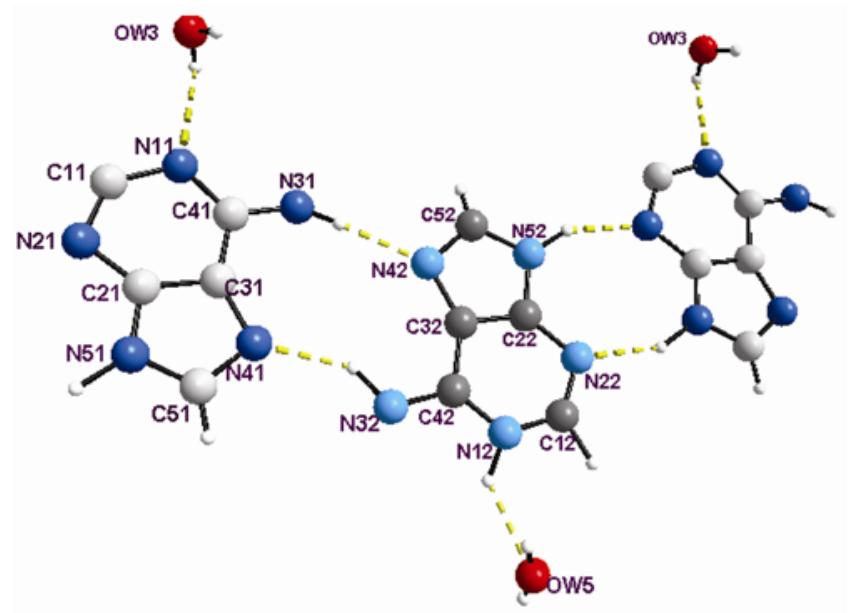

Figure 3. Geometry and environment of the amine molecules in $\mathrm{H}\left(\mathrm{C}_{5} \mathrm{~N}_{5} \mathrm{H}_{5}\right)_{2}\left(\mathrm{C}_{5} \mathrm{~N}_{5} \mathrm{H}_{6}\right)_{2}\left[\mathrm{Al}\left(\mathrm{OH}_{6}\right) \mathrm{Mo}_{6} \mathrm{O}_{18}\right] \cdot 10 \mathrm{H}_{2} \mathrm{O}$.

lattice water molecules. $\left[\mathrm{Al}(\mathrm{OH})_{6} \mathrm{Mo}_{6} \mathrm{O}_{18}\right]^{3-}$ clusters and adenine molecules are used to obtain the 3D supramolecular structure. The typical hydrogen bonds between the polyoxoanions are shown in figure S2(a); neighbouring polyoxoanions are connected by the water bridge. In figure S2(b), the adenine bases are bridged by water molecules.

\subsection{Infrared spectroscopy}

IR spectrum of compound 1 is shown in figure S3. Both characteristic peaks for the Anderson polyoxoanions and the adenine molecules can be observed. The characteristic peaks at $946,892,800,659,579$ and $451 \mathrm{~cm}^{-1}$ for 1 could 
Table 4. Selected hydrogen bonds.

\begin{tabular}{|c|c|c|c|c|}
\hline D-H...A & D-H & H...A & D...A & $\langle\mathrm{DHA}\rangle$ \\
\hline O1-H1...OW4 & $0 \cdot 80$ & $1 \cdot 89$ & $2 \cdot 69$ & $170 \cdot 8$ \\
\hline $\mathrm{O} 2-\mathrm{H} 2 \ldots \mathrm{OW} 1$ & $0 \cdot 81$ & $1 \cdot 82$ & $2 \cdot 61$ & $161 \cdot 1$ \\
\hline O3-H3 ...O10 & $0 \cdot 75$ & $2 \cdot 11$ & $2 \cdot 86$ & $169 \cdot 5$ \\
\hline N31-H4 ...N42 & $0 \cdot 806$ & $1 \cdot 893$ & $2 \cdot 692$ & $170 \cdot 83$ \\
\hline N51-H6...N22 & $1 \cdot 101$ & $2 \cdot 091$ & $3 \cdot 111$ & $152 \cdot 78$ \\
\hline N12-H7 ...OW5 & 1.003 & 1.987 & $2 \cdot 791$ & $135 \cdot 34$ \\
\hline N32-H9...N41 & $1 \cdot 061$ & $2 \cdot 000$ & $2 \cdot 869$ & $136 \cdot 96$ \\
\hline N52-H11 ...N21 & $1 \cdot 032$ & $2 \cdot 075$ & $3 \cdot 039$ & $154 \cdot 38$ \\
\hline OW1-H1W1...OW5 & $0 \cdot 801$ & $2 \cdot 516$ & $3 \cdot 102$ & $131 \cdot 19$ \\
\hline OW1-H1W1...OW4 & $0 \cdot 801$ & $2 \cdot 602$ & $3 \cdot 354$ & $157 \cdot 07$ \\
\hline $\mathrm{OW} 1-\mathrm{H} 2 \mathrm{~W} 1 \ldots \mathrm{OW} 3$ & $0 \cdot 982$ & $1 \cdot 870$ & $2 \cdot 800$ & $156 \cdot 84$ \\
\hline OW1-H2W1...OW3 & $0 \cdot 982$ & $1 \cdot 870$ & $2 \cdot 800$ & $156 \cdot 84$ \\
\hline OW2-H1W2...O6 & 0.797 & $2 \cdot 085$ & $2 \cdot 785$ & $146 \cdot 50$ \\
\hline OW2-H1W2...O11 & 0.797 & $2 \cdot 586$ & $3 \cdot 157$ & $129 \cdot 91$ \\
\hline OW2-H2W2...O4 & $0 \cdot 939$ & 1.953 & $2 \cdot 864$ & $162 \cdot 91$ \\
\hline OW3-H1W3...OW1 & $0 \cdot 884$ & $2 \cdot 163$ & $2 \cdot 800$ & $128 \cdot 54$ \\
\hline OW3-H2W3...OW6 & $0 \cdot 850$ & $2 \cdot 457$ & $3 \cdot 161$ & $140 \cdot 74$ \\
\hline OW3-H2W3...N11 & $0 \cdot 850$ & $2 \cdot 504$ & $2 \cdot 838$ & $130 \cdot 32$ \\
\hline OW4-H1W4...OW5 & $0 \cdot 901$ & 1.959 & $2 \cdot 819$ & $159 \cdot 10$ \\
\hline OW4-H1W4...OW6 & $0 \cdot 901$ & $2 \cdot 170$ & $2 \cdot 824$ & $128 \cdot 95$ \\
\hline OW4-H2W4...OW5 & $1 \cdot 052$ & 1.997 & $2 \cdot 821$ & $132 \cdot 93$ \\
\hline OW5-H1W5...O5 & $0 \cdot 648$ & $2 \cdot 121$ & $2 \cdot 731$ & $157 \cdot 33$ \\
\hline OW5-H2W5 ...N12 & $0 \cdot 710$ & $2 \cdot 316$ & $2 \cdot 791$ & $125 \cdot 74$ \\
\hline OW6-H2W6...OW2 & $0 \cdot 961$ & $2 \cdot 390$ & $2 \cdot 989$ & $120 \cdot 00$ \\
\hline
\end{tabular}

be ascribed to the Anderson polyoxoanions, which are similar to those reported in literature (Shivaiah et al 2002; Drewes et al 2004; An et al 2005b; Gao et al 2006). The bands in the range of $1100-1987 \mathrm{~cm}^{-1}$ could be ascribed to the stretching vibration modes of $v(\mathrm{C}-\mathrm{N})$ and $v(\mathrm{C}-\mathrm{C})$ groups. The presence of strong band at $1623 \mathrm{~cm}^{-1}$ corresponds to bending vibrations of the $\mathrm{OH}$ groups of the water molecules. A broad band extending from 3300 to $2390 \mathrm{~cm}^{-1}$ is observed in the IR spectrum. This broad band must be due to the symmetric and asymmetric stretching modes of $\mathrm{NH}, \mathrm{CH}$ and $\mathrm{OH}$.

\section{$3.3 \quad U V$-Visible spectra}

$\mathrm{UV}-\mathrm{V}$ is spectrum is recorded in aqueous solution at a concentration of $10^{-3} \mathrm{~mol} \mathrm{~L}^{-1}$. The resulting spectrum is shown in figure S4. UV spectra have two absorption bands, the strong absorption band at ca. $215 \mathrm{~nm}$ is attributed to the charge transfer of Mo-Ot and the absorption band at ca. $268 \mathrm{~nm}$ is attributed to that of $\mathrm{Mo}-\mathrm{Ob}$ and Mo-Oc (An et al 2005, 2006, 2007).

\subsection{Thermal behaviour}

Figure S5 shows both TG and DTA thermograms of 1. TG curve of the title compound shows that three steps occur for the loss of water molecules. First step occurs in the range of $40-85^{\circ} \mathrm{C}$ (weight loss, obs. $2 \cdot 38 \%$, cal. $2 \cdot 09 \%$ ) corresponding to the loss of two $\mathrm{H}_{2} \mathrm{O}$ molecules; second step: $85-175^{\circ} \mathrm{C}$ (weight loss, obs. $5 \cdot 52 \%$, cal. $5 \cdot 24 \%$ ) corresponding to the loss of five $\mathrm{H}_{2} \mathrm{O}$ molecules; and the third step: $175-275^{\circ} \mathrm{C}$ (obs. 6.14\%, cal. $6 \cdot 29 \%$ ) corresponding to the loss of six $\mathrm{H}_{2} \mathrm{O}$ molecules. Ten water molecules are the lattice water molecules and the rest water molecules are the so-called constituting water molecules corresponding to the $-\mathrm{OH}$ groups in the anion. This dehydration is related to the first three endothermic peaks on the DTA curve at 64,132 and $250^{\circ} \mathrm{C}$. Compound 1 can lose non-coordinated water molecules in part at room temperature. The error is due to the fact that crystal easily loses lattice $\mathrm{H}_{2} \mathrm{O}$ at room temperature. The following stage representing a set of endotherms from 275 to $450{ }^{\circ} \mathrm{C}$ is assigned to the degradation of the organic cations. This progressive pyrolysis is indicated, in the TGA curve, by a continuous weight loss.

\section{Conclusions}

Recently, studies of polyoxometalates have been improved, which show that the POMs get more and more attention. We have successfully synthesized a new compound based on the Anderson-type $\left[\mathrm{Al}(\mathrm{OH})_{6} \mathrm{Mo}_{6} \mathrm{O}_{18}\right]^{3-}$ polyoxoanion building block by slow evaporation at room temperature. The studies of the title compounds not only afford a preparation route concerning the $\left[\mathrm{Al}(\mathrm{OH})_{6}\right.$ $\left.\mathrm{Mo}_{6} \mathrm{O}_{18}\right]^{3-}$, but also expand the family of hybrid materials from a structural point of view.

\section{Acknowledgements}

The crystal data collection of $\mathrm{H}\left(\mathrm{C}_{5} \mathrm{~N}_{5} \mathrm{H}_{6}\right)_{2}\left(\mathrm{C}_{5} \mathrm{~N}_{5} \mathrm{H}_{6}\right)_{2}$ $\left[\mathrm{Al}\left(\mathrm{OH}_{6}\right) \mathrm{Mo}_{6} \mathrm{O}_{18}\right] \cdot 10 \mathrm{H}_{2} \mathrm{O}$ was done in the 'Laboratoire de Matériaux et Cristallochimie, Faculté des Sciences, El Manar, 2092, Tunis, Tunisia'. We are grateful to Ahmed Driss, who supervised this experiment.

\section{Supplementary material}

CCDC 886339 contains the supplementary crystallographic data for this paper. These data can be obtained free of charge via http://www.ccdc.cam.ac.uk/data request/cif, by e-mailing data_request@ccdc.cam.ac.uk or by contacting The Cambridge Crystallographic Data Centre, 12 Union Road, Cambridge CB2 1EZ, UK. Fax: +44 1223336033.

Supplementary material pertaining to this article is available on the Bulletin of Materials Science website (www.ias.ac.in/matersci).

\section{References}

An H Y, Guo Y Q, Li Y G, Xu L and Hu C G 2004 Inorg. Chem. Commun. 7521

An H Y, Li Y G, Wang E, Sun C Y and Xu L 2005a J. Mol. Struct. 743117

An H Y, Li Y G, Wang E B, Xiao D R, Sun C Y and Xu L 2005b Inorg. Chem. 446062 
An H Y, Xiao D R, Sun C Y, Li Y G and Xu L 2005c J. Mol. Struct. 751184

An H Y, Li Y G, Xiao D R, Wang E B and Sun C Y 2006 Cryst. Growth. Des. 61107

An H Y, Xu T Q, Wang E B and Meng C G 2007 Inorg. Chem. Commun. 101453

An H Y, Han Z B, Xu T Q and Wang E 2008 Inorg. Chem. Commun. 11914

An H, Xu T, Jia C, Zheng H and Mu W 2009 J. Mol. Struct. 93386

CAD-4 Express Software 1994 Enraf-Nonius Delft, The Netherlands

Clemente-Juan J M and Coronado E 1999a Chem. Rev. 193361

Clemente-Juan J M and Coronado E 1999b Chem. Rev. 361193

Drewes D, Limanski E M and Krebs B 2004 J. Chem. Soc. Dalton Trans. 142087

Finn R and Zubieta J 2000 Chem. Commun. 1321

Gao B, Liu S X, Xie L H and Cheng H Y 2006 J. Solid State Chem. 1791681

Gomez-Garcia C J, Ouahab L and Delhaes P 1994 Angew. Chem. Int. Ed. Engl. 33223

Hagraman P J, Hagraman D and Zubieta J 1999 Angew. Chem. Int. Ed. Engl. 382638

He T and Yao J 2006 Prog. Mater. Sci. 51810

Hingerty B E, Einstein J R and Wie C H 1981 Acta Crystallogr. B37 140

Hui M, Li-Zhou W and Hai P 2010 J. Mol. Struct. 96715

Keita B, Nadjo L and Stratmann M (eds) 2006 Encyclopedia of electrochemistry (Wiley) vol. 7 p 123

Kozhenikov I V 1998 Chem. Rev. 98171

Li Y G, Wang E B, Wang S T, Lu Y, Hu C W and Hu N H 2002 J. Mol. Struct. 607133
Luan G Y, Wang E B, Li Y G, Hu C W and Hu N H 2002 J. Mol. Struct. 606211

Ma P, Chen L, Zhao J, Wang W, Wang J and Niu J 2011 Inorg. Chem. Commun. 14415

Mohamed T A, Shabaan I A and Alajhaz A M A 2009 J. Mol. Struct. 938263

Ouahab L, Iwahori F, Golhen S, Carlier R and Sutter J P 2003 Synthetic Metals 133505

Peng J, Xin L, Zhou Y S and Li W Z 1999 Polyhedron 183147

Perloff A 1970 Inorg. Chem. 92228

Pope M T 1983 Heteropoly and isopolyoxometalates (Berlin: Springer)

Proust A, Thouvenot R and Gouzerh P 2008 Chem. Commun. 161837

Ren Y P, Kong X J and Sun M 2006 Inorg. Chem. 454016

Sheldrick G M 1997 SHELXL97. Program for the refinement of crystal structures (Federal Republic of Germany: University of Göttingen)

Shivaiah V, Reddy P V N and Cronin L 2002 J. Chem. Soc. Dalton Trans. 203781

Softbv web page by Prof. Stefan Adams, (http://kristall.uni. mki.gwdg.de/softbv)

Taylor M R 1973 Acta Crystallogr. B29 884

Thabet S, Ayed B and Haddad A 2012 Mater. Res. Bull. 473791

Wang S, Chen W and Wang E 2010 J. Clust. Sci. 21145

Xia Q, Lin X and Yanyan Y 2011 J. Struct. Chem. 22965

Xiao D, An H, Wang E and Xu L 2005 J. Mol. Struct. 738217

Yan D, Chen Q, Xu Y, Sun Q, Zhu O, Song Y and Elangovan S P 2011 Inorg. Chem. Commun. 141314 